\title{
BMJ Open Trends in asthma hospital admissions and mortality in Kuwait, 2000-2014: a national retrospective observational study
}

\author{
Ali H Ziyab, ${ }^{1}$ Adnan T Abul ${ }^{1,2}$
}

To cite: Ziyab AH, Abul AT. Trends in asthma hospital admissions and mortality in Kuwait, 2000-2014: a national retrospective observational study. BMJ Open 2018;8:e021244. doi:10.1136/ bmjopen-2017-021244

- Prepublication history and additional material for this paper are available online. To view these files, please visit the journal online (http://dx.doi. org/10.1136/bmjopen-2017021244).

Received 18 December 2017 Revised 8 March 2018 Accepted 9 April 2018
Check for updates

${ }^{1}$ Department of Community Medicine and Behavioral Sciences, Faculty of Medicine, Kuwait University, Safat, Kuwait ${ }^{2}$ Department of Medicine, Faculty of Medicine, Kuwait University, Safat, Kuwait

Correspondence to

Dr Ali H Ziyab;

aziyab@hsc.edu.kw

\section{ABSTRACT}

Objectives To examine trends in asthma hospitalisation and mortality rates from 2000 to 2014 in Kuwait according to sex, age and nationality.

Methods For this nationwide, retrospective observational study, data from hospital discharge records and death certificates listing asthma as the primary reason for hospitalisation or mortality were obtained from the National Center for Health Information database using International Classification of Diseases, Tenth Revision codes J45 and J46. Trends in sex-adjusted, age-adjusted and nationality-adjusted hospitalisation and mortality rates were examined. Poisson regression models were applied to test for linear trends overtime and estimate adjusted rate ratios and $95 \% \mathrm{Cl}$.

Results During the 15-year study period, a total of 43652 hospitalisations and 484 deaths due to asthma exacerbations were identified. The average annual adjusted rates of asthma hospitalisation and mortality were estimated to be 134.9 (95\% $\mathrm{Cl} 131.8$ to 138.1$)$ and $2.1(95 \% \mathrm{Cl} 1.8$ to 2.4) per 100000 population, respectively. Hospitalisation rates decreased by $49.5 \%$ in the total population (from 180.8 to 91.3 admissions per 100000 population between 2000 and 2014, $p_{\text {trend }}<0.001$ ) and by $57.9 \%$ in the age group of $5-44$ years (from 77.3 to 32.5 admissions per 100000 population, $p_{\text {trend }}<0.001$ ). Mortality rates decreased from 4.1 to 0.9 deaths per 100000 population between 2000 and 2014 in the total population $\left(77.6 \%\right.$ decrease, $\left.p_{\text {trend }}<0.001\right)$ and from 0.6 to 0.2 deaths per 100000 population among those aged $5-44$ years $\left(61.9 \%\right.$ reduction, $\left.p_{\text {trend }}=0.005\right)$. Kuwaiti compared with non-Kuwaiti subjects had higher risk of asthma hospitalisation and mortality. Among children aged $\leq 19$ years, the risk of hospitalisation was higher in boys compared with girls; however, among adults, women experienced more hospitalisations than men.

Conclusions Asthma hospitalisation and mortality rates have substantially decreased between 2000 and 2014 in Kuwait, with persisting differences between genders, age groups and citizens versus non-citizens. The observed decreasing trends in Kuwait are in agreement with global trends.

\section{INTRODUCTION}

Asthma is the most common inflammatory chronic disorder of the lungs that affects children and adults. Globally, it was estimated in 2015 that 358 million people suffer from

\section{Strengths and limitations of this study}

This study provided, at a national level, a comprehensive perspective on trends and disparities in hospitalisations and mortality related to asthma exacerbations in Kuwait over a 15-year period.

- Although data analysed in the current report were obtained from the National Center for Health Information database using International Classification of Diseases, Tenth Revision codes $\mathrm{J} 45$ and J46, misclassification of asthma-related hospitalisations or deaths is inevitable in epidemiological studies based on routinely collected data, which could either underestimate or overestimate the frequency.

- Lack of information on ethnicity/race of patients is a further limitation to our study.

asthma, which reflects a $12.6 \%$ increase in asthma prevalence compared with $1990{ }^{1}$ Whereas asthma-related mortality, causing 397000 deaths in 2015 , decreased by $26.7 \%$ between 1990 and 2015. ${ }^{1}$ The International Study of Asthma and Allergies in Childhood revealed variations in the prevalence of asthma both between and within countries. ${ }^{2}$ For instance, among children aged 13-14 years, the 12-month prevalence of asthma symptoms ranged from $3.4 \%$ to $31.2 \% .^{3}$ In westernised countries, asthma is usually seen in around $10 \%$ of the general population. ${ }^{4}$ Hence, due to the elevated prevalence, morbidity and mortality, asthma is considered a global public health problem.

The major pathophysiological hallmarks that contribute to the complex heterogeneity of the clinical manifestations of asthma include recurrent airway inflammation, variable airway obstruction and bronchial hyper-responsiveness. ${ }^{5}$ Asthma exacerbations, defined as 'a worsening of asthma requiring the use of systemic corticosteroids to prevent a serious outcome', have been graded in severity from mild to severe and in some instances as life-threatening. ${ }^{6}{ }^{7}$ Exacerbations requiring emergency department 
visits and hospitalisations are associated with substantial morbidity, medical expenditures and economic as well as social burden on individuals and families. ${ }^{6}$ In principle, asthma exacerbations are preventable events in the presence of high-quality healthcare, patient awareness and compliance, and optimal asthma management.

In Kuwait, the burden of asthma is comparable to what is observed in western nations. For instance, 7.6\% and $15.6 \%$ of schoolchildren aged 13-14 years reported current wheeze and ever doctor-diagnosed asthma, respectively. ${ }^{9}$ A recent study showed that $11.9 \%$ of university students in Kuwait suffer from asthma. ${ }^{10}$ Annually, asthma management and treatment cause a considerable financial burden, costing US $\$ 207$ million with hospital admissions accounting for $43 \%$ of the total direct costs for asthma treatment in Kuwait. ${ }^{11}$ During the period from 1992 to 1994, the annual rates of asthma hospitalisation and mortality in Kuwait were estimated to be 205 admissions and 1.59 deaths per 100000 population, respectively. ${ }^{12}$ Given the ongoing improvements in asthma therapeutic and management strategies, we hypothesised that asthma hospitalisations and mortality have decreased; however, there have been no recent efforts to assess temporal trends in Kuwait. Therefore, this study sought to describe the trends in asthma hospital admissions and mortality according to sex, age and nationality in Kuwait between 2000 and 2014 using national hospital discharge records and death certificates.

\section{METHODS}

\section{Study setting}

Kuwait, a small country with a total approximate area of $18000 \mathrm{~km}^{2}$, is located in the Arabian Peninsula with sandy desert covering its landscape. Generally, the climate in Kuwait is arid with extreme hot temperatures during summer and mild-cool weather in winter and frequent dust storms that occur throughout the year. ${ }^{13}$ As of June 2017, the total population was estimated to be around 4.4 million. The population of Kuwait can be divided into two separate communities, namely citizens of Kuwait (Kuwaitis) and labour migrants/expatriates (non-Kuwaitis). Kuwaitis make around 30\% (1.3 million) of the population, whereas non-Kuwaitis constitute about $70 \%$ (3.1 million) of the population. The majority of the non-Kuwaitis are of Asian ethnicity (1.8 million) and Arab ethnicity (1.2 million). Demographically, the majority of expatriates are males $(65 \%)$, poorly educated $(70 \%$ with less than secondary level education) and relatively young (83\% aged between 15 and 60 years). ${ }^{14}$ Hence, distorting the demographic distribution of this population towards male and working-age predominance.

Healthcare services in Kuwait are divided into primary, secondary and tertiary care. There are six public general hospitals, providing secondary level care, across Kuwait equipped with child and adult emergency departments. Moreover, at a smaller scale, some private hospitals provide emergency care services.

\section{Study design, data sources and outcomes}

In this nationwide, retrospective observational study, we analysed data from hospital discharge records and death certificates on asthma for the period from 1 January 2000 to 31 December 2014. Public and private hospitals across the state of Kuwait are required to report health and vital statistics data on regular bases to the National Center for Health Information (NCHI) at the Ministry of Health. In this study, data were collected from all hospital discharge records and death certificates listing asthma as the primary reason for admission or death using the International Classification of Diseases, Tenth Revision codes: J45 (asthma, including predominantly allergic asthma, non-allergic asthma, mixed asthma, asthma unspecified) and J46 (status asthmaticus). In the data extraction process, we included all anonymised asthma-related hospital admission episodes or mortality and collected data on age, sex and nationality using the NCHI database. If a person has been hospitalised several times for asthma, we counted and considered all admissions per person as independent events. Annual midyear population estimates, total and stratified according to sex, age and nationality, were obtained from the Public Authority for Civil Information, Kuwait.

\section{Statistical analysis}

Counts of asthma hospital admissions and deaths resembled the unit of analysis. Five age groups were defined: $<5$ years, 5- 19 years, $20-44$ years, $45-64$ years and $\geq 65$ years. Annual and average annual rates of asthma hospital admissions and mortality per 100000 population were estimated for the 15-year study period (from 1 January 2000 to 31 December 2014) for the total population and stratified according to age group, sex and nationality. In trend analysis, using calendar year as the exposure variable of interest, annual changes in rates of asthma hospital admissions and mortality were examined. Trend analysis was conducted using the total study sample and a subsample restricted to those aged between 5 and 44 years. The rationale for additionally examining trends in those aged 5-44 years was to minimise the effect of misclassification of asthma hospitalisation and mortality among younger and older age groups. ${ }^{15}$ Moreover, per cent change (PC) in hospitalisation and mortality rates comparing the years 2000 and 2014 were calculated as follows: $P C=[($ rate in 2014 - rate in 2000)/rate in 2000) $\times 100$ ]. Poisson regression models, with log link function, were used to calculate overall as well as stratified model-adjusted rates and adjusted rate ratios (aRRs) and their corresponding 95\% CI using the GENMOD procedure in SAS V.9.4 (SAS Institute). Regression-based adjustments for age, sex and nationality were considered when estimating rates and rate ratios. In all regression models, we treated the observed counts of asthma-related hospitalisations/ mortality in each year as the outcome variable and the corresponding denominator (ie, logarithm of midyear population counts) as an offset term. Additionally, sex-standardised and age-standardised asthma hospital 
Table 1 Number and average annual rates of asthma hospital admissions and mortality in Kuwait, 2000-2014

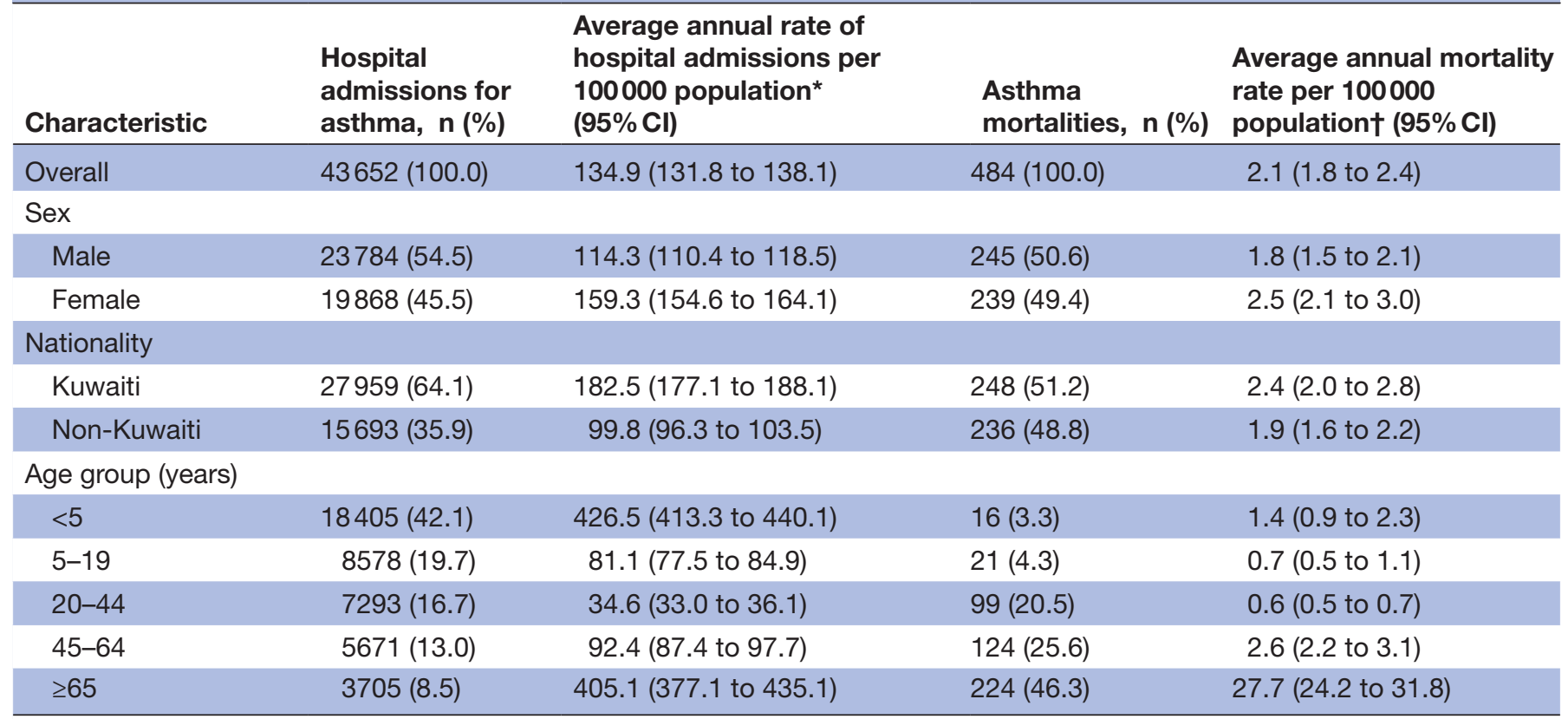

*Model-adjusted average annual hospital admission rates for asthma per 100000 population per year over the period from 2000 to 2014 were calculated using Poisson regression models while adjusting for sex, nationality and age group.

†Model-adjusted average annual mortality rates due to asthma per 100000 population per year over the period from 2000 to 2014 were calculated using Poisson regression models while adjusting for sex, nationality and age group.

admission rates for the total population and stratified according to nationality were calculated using weights from the WHO new World Standard Population. ${ }^{16}$ The STDRATE procedure in SAS V.9.4 was used to compute directly sex-standardised and age-standardised rates. All statistical analyses were conducted using SAS V.9.4. The statistical significance level was set to 0.05 for all association and trend analyses.

\section{Patient and public involvement}

This research did not directly involve patients nor the public since the analysis was based on routinely collected data, that is, data from hospital discharge records and death certificates.

\section{RESULTS}

\section{Characteristics and trends of asthma hospital admissions}

During the 15-year study period, a total of 43652 hospital admissions due to asthma exacerbations were identified from hospital discharge records in Kuwait. Of the total hospital admissions, 23784 (54.5\%) were among males, $27959(64.1 \%)$ were among Kuwaiti individuals and $18405(42.1 \%)$ were among children aged $<5$ years (table 1). The sex, age and nationality model-adjusted average annual rate of asthma hospital admissions was estimated to be 134.9 (95\% CI 131.8 to 138.1) admissions per 100000 population per year. On average, significantly higher hospitalisation rates were observed among females compared with males (159.3 vs 114.3 admissions per 100000 population per year, $\mathrm{p}<0.001)$ and Kuwaiti nationals compared with non-Kuwaiti subjects
(182.5 vs 99.8 admissions per 100000 population per year, $\mathrm{p}<0.001)$. Average annual hospitalisation rates were highest among children aged $<5$ years $(426.5$ admissions per 100000 population) and in adults aged $\geq 65$ years (405.1 admissions per 100000 population), whereas individuals aged 20- 44 years had the lowest average annual hospitalisation rate of 34.6 admissions per 100000 population (table 1).

Trend analysis showed that asthma hospitalisation rates decreased from 180.8 to 91.3 admissions per 100000 population between 2000 and 2014 in the total population (a $49.5 \%$ decrease (95\% CI 44.2 to 54.3), $\mathrm{p}_{\text {trend }}<0.001$; figure $1 \mathrm{~A}$, table 2 ). Significantly decreasing trends were observed in both sexes, with reductions in admissions rates between 2000 and 2014 amounting to $51.8 \%$ in females (from 221.8 to 106.9 admissions per 100000 population, $\left.\mathrm{p}_{\text {trend }}<0.001\right)$ and $47.6 \%$ in males (from 148.5 to 77.9 admissions per 100000 population, $\mathrm{p}_{\text {trend }}<0.001$; figure 1B). Similarly, decreasing trends in asthma hospitalisation rates were evident among Kuwaiti and non-Kuwaiti subjects (figure 1C). Among Kuwaiti subjects, hospitalisation rate decreased from 251.0 to 128.9 admissions per 100000 population between 2000 and 2014; representing a $48.6 \%$ reduction. Among non-Kuwaiti subjects, hospitalisation rate was estimated to be 126.5 admissions per 100000 population in 2000 and decreased to 63.2 admissions per 100000 population in 2014; representing a $50.1 \%$ reduction.

Similar to the observed trends in the total study sample, analysis among those aged between 5 and 44 years (referred to as subsample) showed decreasing trends 

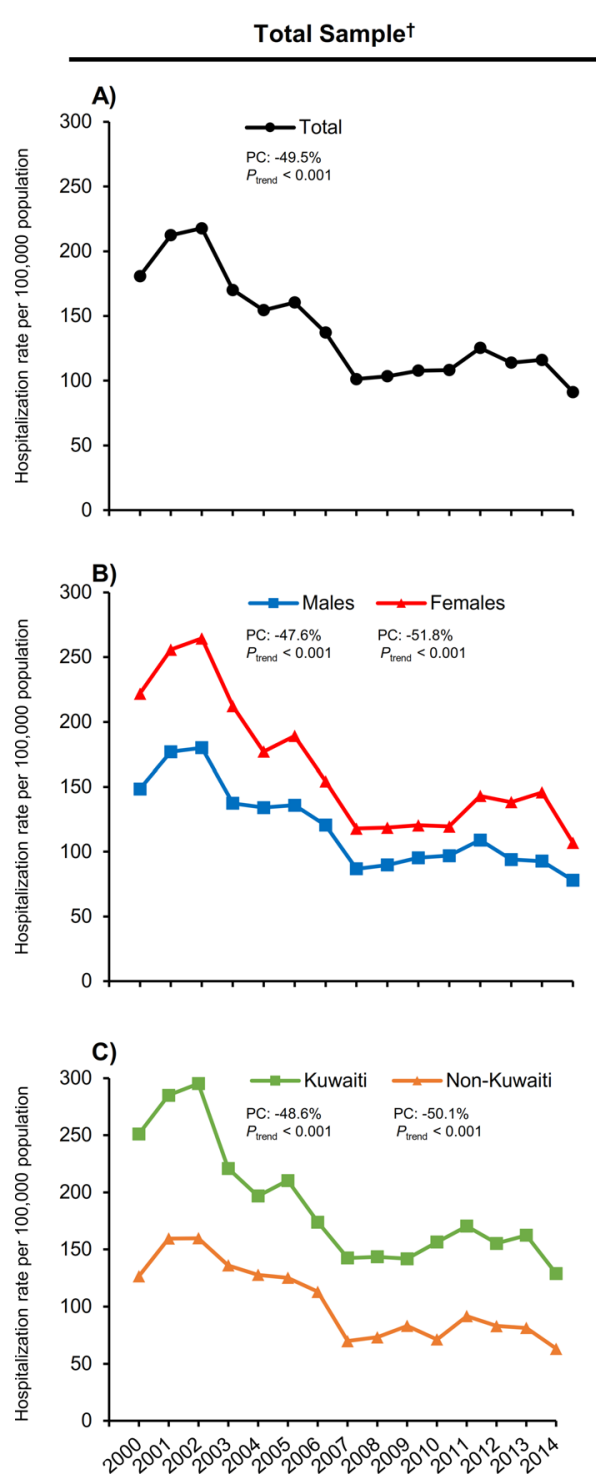

$5-44$ Year Age Group Subsample $\ddagger$

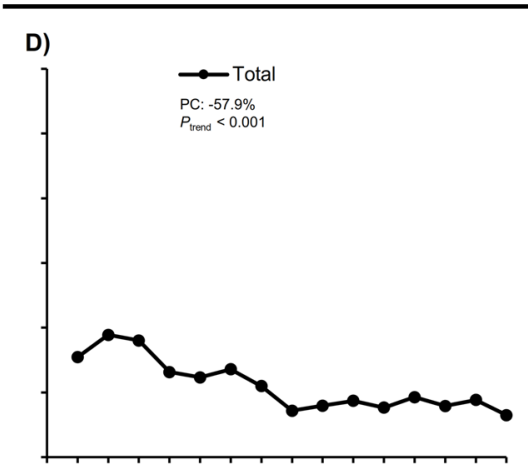

E)

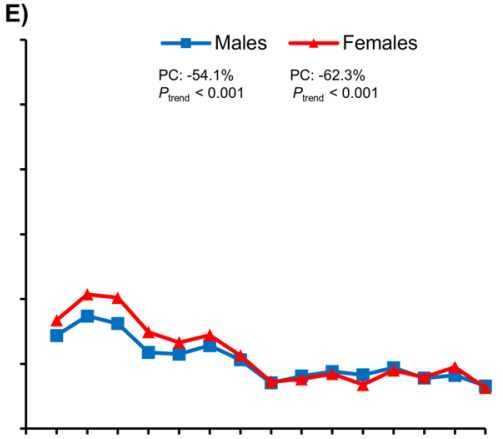

F)

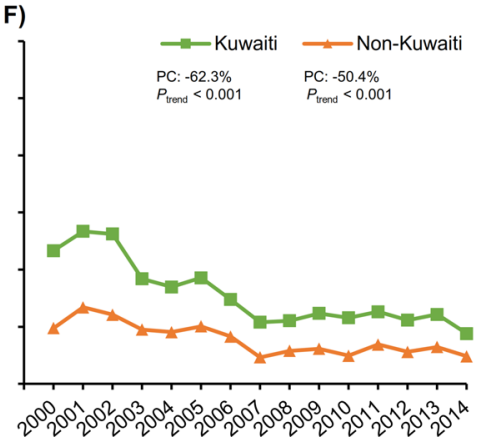

Figure 1 Trends in annual hospital admission rates for asthma per 100000 population in Kuwait, 2000-2014. Asthma hospital admission rates in the ${ }^{\dagger}$ total study sample $(A-C)$ and in a ${ }^{\ddagger}$ subsample restricted to those aged 5-44 years (D-F) are presented. (A) Trends in the total study sample. (B) Sex-stratified trends in the total study sample. (C) Nationality-stratified trends in the total study sample. (D) Trends in the total subsample. (E) Sex-stratified trends in the subsample. (F) Nationality-stratified trends in the subsample. Rates for the total population (A, D) are sex, age and nationality model-adjusted. The sex-stratified rates (B, E) are age and nationality model-adjusted. Nationality-stratified rates (C, F) are age and sex model-adjusted. Per cent change (PC) given as rate in 2014 versus rate in 2000. A negative PC value represents decrease between 2000 and 2014 . P values for linear trend were derived from Poisson regression analysis.

in asthma hospitalisation rates. In the total subsample, hospitalisation rate decreased from 77.3 to 32.5 admissions per 100000 population between 2000 and 2014; representing a $57.9 \%$ reduction (figure 1D). Sex-stratified analysis of the subsample showed that hospitalisation rates have decreased between 2000 and 2014 in both females (from 83.6 to 31.5 admissions per 100000 population, $\mathrm{p}_{\text {trend }}<0.001$ ) and males (from 71.9 to 33.0 admissions per 100000 population, $\mathrm{p}_{\text {trend }}<0.001$; figure $1 \mathrm{E}$ ). Similarly, between 2000 and 2014, decreasing trends in hospitalisation rates were observed among Kuwaiti individuals (from 116.6 to 44.0 admissions per 100000 population, $\mathrm{p}_{\text {trend }}<0.001$ ) and non-Kuwait subjects (from 48.8 to 24.2 admissions per 100000 population, $\mathrm{p}_{\text {trend }}<0.001$; figure $1 \mathrm{~F})$.

Moreover, using the total study sample, decreasing trends in hospital admission rates were observed in most subgroups stratified according to sex, nationality and age group (figure 2). For instance, most pronounced decreases in hospitalisation rates between 2000 and 2014 among both Kuwaiti males and females were observed among those aged 5-19 years (decrease of $63.1 \%$ in males and $70.2 \%$ in females, $p_{\text {trend }}<0.001$ ) compared with other age groups. Whereas non-Kuwaiti males aged $<5$ (49.0\% decrease, $\left.\mathrm{p}_{\text {trend }}<0.001\right)$ and $\geq 65$ (49.2\% decrease, $\left.\mathrm{p}_{\text {trend }}<0.001\right)$ years experienced the highest decreases 
Table 2 Annual rates and rate ratios (RRs) of asthma hospital admissions and mortality in Kuwait, 2000-2014

\begin{tabular}{|c|c|c|c|c|c|c|}
\hline Year & $\begin{array}{l}\text { Hospital } \\
\text { admissions } \\
\text { for asthma, } n\end{array}$ & $\begin{array}{l}\text { Hospital admission rate } \\
\text { per } 100000 \text { population* } \\
(95 \% \mathrm{Cl})\end{array}$ & $\begin{array}{l}\text { Adjusted hospital } \\
\text { admission RR† } \\
(95 \% \mathrm{Cl})\end{array}$ & $\begin{array}{l}\text { Asthma } \\
\text { mortalities, } n\end{array}$ & $\begin{array}{l}\text { Mortality rate } \\
\text { per } 100000 \\
\text { population } ¥ \\
(95 \% \mathrm{Cl})\end{array}$ & $\begin{array}{l}\text { Adjusted mortality } \\
\mathrm{RR} \dagger(95 \% \mathrm{Cl})\end{array}$ \\
\hline 2000 & 3004 & $180.8(168.7$ to 193.8$)$ & 1.00 (reference) & 39 & 4.1 (3.0 to 5.6$)$ & 1.00 (reference) \\
\hline 2001 & 3557 & 212.4 (199.3 to 226.4) & 1.18 (1.07 to 1.29$)$ & 37 & 3.3 (2.4 to 4.6$)$ & 0.81 (0.52 to 1.25$)$ \\
\hline 2002 & 3755 & 217.7 (204.6 to 231.7) & 1.20 (1.10 to 1.32$)$ & 51 & 4.9 (3.6 to 6.6$)$ & 1.19 (0.79 to 1.78$)$ \\
\hline 2004 & 2860 & 154.5 (144.0 to 165.9$)$ & 0.86 (0.78 to 0.94$)$ & 21 & 2.3 (1.5 to 3.5$)$ & 0.56 (0.34 to 0.93$)$ \\
\hline 2005 & 3133 & $160.4(149.9$ to 171.6$)$ & 0.89 (0.81 to 0.97$)$ & 37 & 2.6 (1.8 to 3.6$)$ & 0.62 (0.41 to 0.96$)$ \\
\hline 2006 & 2819 & $137.2(127.7$ to 147.2$)$ & 0.76 (0.69 to 0.84$)$ & 43 & 2.5 (1.9 to 3.4 ) & 0.61 (0.40 to 0.92 ) \\
\hline 2007 & 2215 & 101.3 (93.6 to 109.8$)$ & 0.56 (0.51 to 0.62$)$ & 40 & 2.5 (1.8 to 3.6$)$ & 0.60 (0.39 to 0.92$)$ \\
\hline 2011 & 3149 & $125.3(117.1$ to 134.0$)$ & 0.69 (0.63 to 0.76$)$ & 16 & 1.4 (0.9 to 2.2$)$ & 0.33 (0.19 to 0.58$)$ \\
\hline 2012 & 2976 & 113.9 (106.3 to 122.0$)$ & 0.63 (0.57 to 0.69$)$ & 14 & 0.9 (0.5 to 1.4$)$ & 0.21 (0.12 to 0.38$)$ \\
\hline 2013 & 3122 & 116.1 (108.5 to 124.2$)$ & 0.64 (0.58 to 0.71$)$ & 14 & 0.8 (0.5 to 1.3$)$ & 0.19 (0.11 to 0.34$)$ \\
\hline 2014 & 2533 & 91.3 (84.8 to 98.4$)$ & 0.51 (0.46 to 0.56$)$ & 13 & $0.9(0.5$ to 1.6$)$ & $0.22(0.12$ to 0.41$)$ \\
\hline
\end{tabular}

*Model-adjusted hospital admission rates for asthma per 100000 population were calculated using Poisson regression models while adjusting for sex, nationality and age group.

†Rate ratios compared with 2000 (the reference year) are adjusted for age, sex and nationality.

$\ddagger$ Model-adjusted mortality rates due to asthma per 100000 population were calculated using Poisson regression while adjusting for sex, nationality and age group.

in hospitalisation rates. Among non-Kuwaiti females, those aged $45-64$ years had a $64.8 \%$ decrease in asthma hospital admissions between 2000 and 2014 ( $\mathrm{p}_{\text {trend }}<0.001$; figure 2).

\section{Characteristics and trends of asthma mortality}

A total of 484 asthma deaths were identified over the 15 -year study period in Kuwait (table 1). Of the total deaths, $245(50.6 \%)$ were among males, 248 (51.2\%) were among Kuwaiti individuals and 224 (46.3\%) were among individuals aged $\geq 65$ years (table 1 ). The average annual adjusted asthma mortality rate was estimated to be 2.1 (95\% CI 1.8 to 2.4) deaths per 100000 population per year. On average, significantly higher mortality rates were observed among females compared with males (2.5 vs 1.8 deaths per 100000 population per year, $\mathrm{p}<0.001$ ) and Kuwaiti nationals compared with non-Kuwaiti subjects (2.4 vs 1.9 deaths per 100000 population per year, $\mathrm{p}=0.010$ ). Average annual mortality rate was highest among individuals aged $\geq 65$ years (27.7 deaths per 100000 population) and least among those aged 20-44 years (0.6 deaths per 100000 population; table 1 ).

Across the study period, asthma mortality rates decreased from 4.1 to 0.9 deaths per 100000 population between 2000 and 2014 in the total population; translating to a $77.6 \%$ (95\% CI 58.9 to $\left.87.8, \mathrm{p}_{\text {trend }}<0.001\right)$ reduction (figure $3 \mathrm{~A}$, table 2). Among males, asthma mortality rates decreased from 4.1 to 0.5 deaths per 100000 population between 2000 and 2014. Whereas among females, asthma mortality rates reduced from 4.3 to 1.4 deaths per 100000 population between 2000 and 2014. Hence, the magnitude of reduction in mortality rates was higher among males $(89.0 \%$ decrease) compared with females (67.4\% decrease; figure 3B). Moreover, decreasing trends between 2000 and 2014 in asthma mortality rates were evident among Kuwaiti subjects (from 4.6 to 1.1 deaths per 100000 population, $\left.\mathrm{p}_{\text {trend }}<0.001\right)$ and non-Kuwaiti individuals (from 3.9 to 0.6 deaths per 100000 population, $\mathrm{p}_{\text {trend }}<0.001$; figure $3 \mathrm{C}$ ).

Furthermore, trends in asthma mortality were examined in a subsample restricted to those aged between 5 and 44 years. In the total subsample, asthma mortality rates decreased from 0.6 to 0.2 deaths per $100000 \mathrm{popu}-$ lation between 2000 and 2014; representing a $61.9 \%$ reduction $\left(\mathrm{p}_{\text {trend }}=0.005\right.$; figure $\left.3 \mathrm{D}\right)$. Mortality rates among females aged 5-44 years showed decreasing trends across the study period (from 0.7 to 0.3 deaths per 100000 population, $\mathrm{p}_{\text {trend }}=0.005$; figure $3 \mathrm{E}$ ). In contrast, mortality rates among males aged 5-44 years did not demonstrate statistically significant decreasing trends $\left(\mathrm{p}_{\text {trend }}=0.207\right.$; figure $3 \mathrm{E}$ ). Although the decreasing trends in nationality-stratified mortality rates in the subsample did not gain statistical significance, the magnitude of reduction between 2000 and 2014 was higher among non-Kuwaiti subjects $\left(77.9 \%\right.$ decrease, $\left.\mathrm{p}_{\text {trend }}=0.071\right)$ compared with Kuwaiti individuals $\left(18.4 \%\right.$ decrease, $\mathrm{p}_{\text {trend }}=0.066$; figure $3 \mathrm{~F})$. 


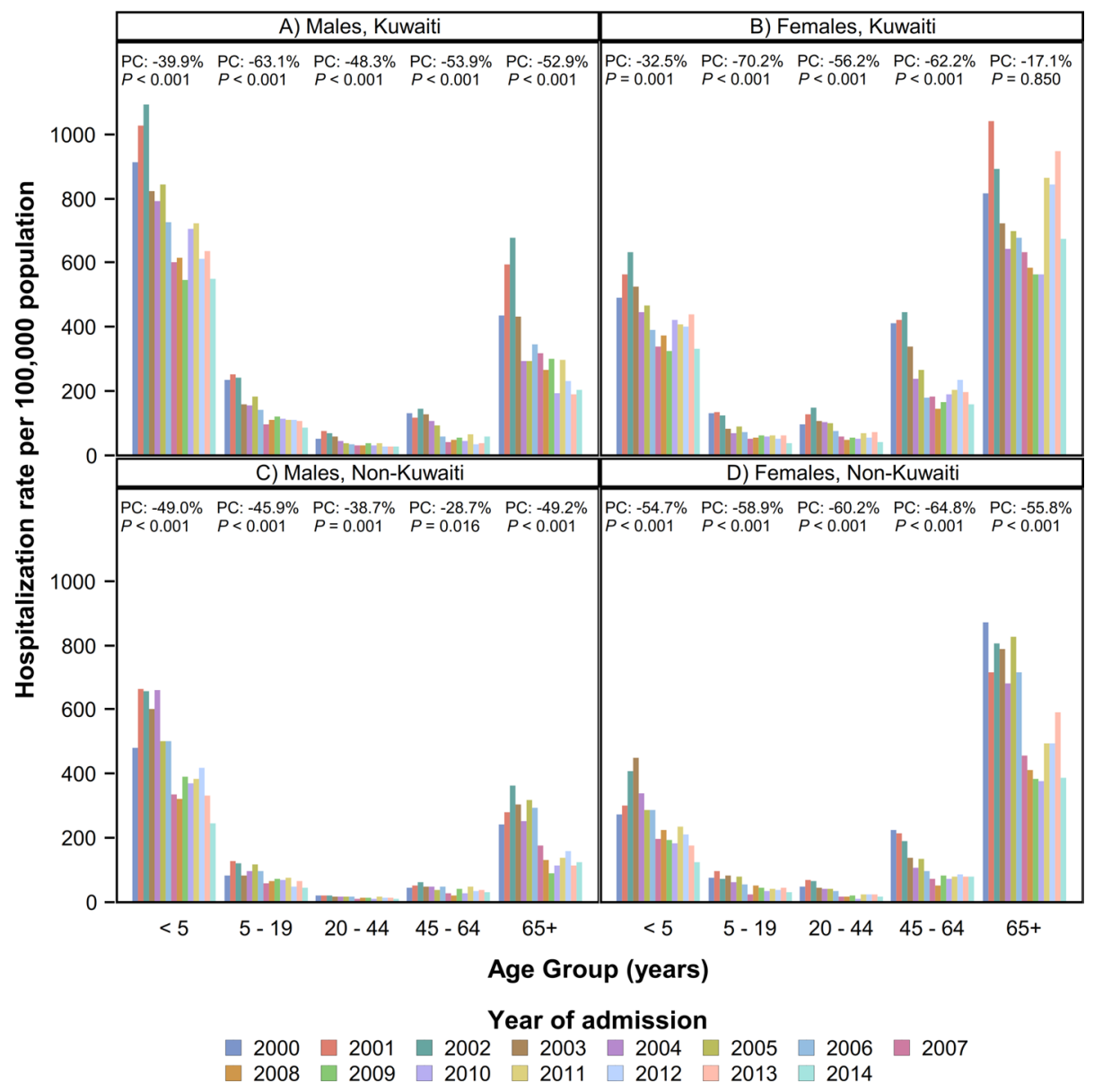

Figure 2 Age-specific, sex-specific and nationality-specific trends in annual hospital admission rates for asthma per 100000 population in Kuwait, 2000-2014. (A) Rates among males of Kuwaiti nationality. (B) Rates among females of Kuwaiti nationality. (C) Rates among males of non-Kuwaiti nationality. (D) Rates among females of non-Kuwaiti nationality. Per cent change (PC) given as rate in 2014 versus rate in 2000. A negative per cent change value represent decrease between 2000 and 2014. $P$ values for linear trend were derived from Poisson regression analysis.

\section{Associations between nationality and asthma hospitalisation and mortality rates}

In regard to nationality disparity in asthma hospitalisation, Kuwaiti nationals compared with non-Kuwaiti subjects had higher risk of asthma hospital admission in the total population ( $\mathrm{aRR}=1.83,95 \%$ CI 1.75 to 1.92 ). Moreover, our analysis showed that both males and females of Kuwaiti nationality had higher asthma hospitalisation rates compared with non-Kuwaitis across all age groups (see online supplementary table S1). Overall, Kuwaiti males had 1.81 times (95\% CI 1.69 to 1.94 ) the risk of hospitalisation compared with non-Kuwaiti males. Similarly, Kuwaiti females had 1.88 times (95\% CI 1.72 to 2.06; see online supplementary table S1) the risk of hospitalisation compared with non-Kuwaiti females.

In regard to asthma mortality, Kuwaiti individuals compared with non-Kuwaiti subjects had higher mortality rate $(\mathrm{aRR}=1.29$, 95\% CI 1.06 to 1.56$)$. Sex-stratified analysis showed that the risk of asthma mortality is similar between Kuwaiti females and non-Kuwaiti females ( $\mathrm{aRR}=0.85$, 95\% CI 0.67 to 1.08$)$. In contrast, Kuwaiti males had 1.99 times (95\% CI 1.48 to 2.68) the risk of asthma mortality compared with non-Kuwait males.
Sex differences in asthma hospitalisation and mortality rates Overall, females had higher risk of asthma hospitalisation compared with males ( $\mathrm{aRR}=1.39,95 \%$ CI 1.33 to 1.46). However, the sex ratio of asthma hospitalisation varied significantly across age groups (figure 4 ). Among children aged $\leq 19$ years, the risk of hospital admission for asthma was significantly lower in females compared with males (age <5 years: $\mathrm{RR}_{\text {female vs male }}=0.58,95 \% \mathrm{CI}$ 0.54 to 0.63 ; age $5-19$ years: $\mathrm{RR}_{\text {female vs male }}=0.56,95 \% \mathrm{CI}$ 0.51 to 0.62 ). On the contrary, among those aged $\geq 20$ years, asthma hospitalisation risk was significantly higher in females compared with males. For instance, among those aged 20-44 years, females had 1.99 times (95\% CI 1.76 to 2.26) the risk of hospitalisation compared with males. These sex-specific and age-specific associations were similar for Kuwaiti and non-Kuwaiti subjects (figure 4).

In general, the risk of asthma mortality was higher among females compared with males ( $\mathrm{aRR}=1.41,95 \% \mathrm{CI}$ 1.19 to 1.68$)$. In age-stratified analysis, mortality rates were higher among females compared with males among those aged $5-19$ years $\left(\mathrm{aRR}_{\text {female vs male }}=1.51,95 \%\right.$ CI 0.98 to 2.32), 20-44 years $\left(\mathrm{aRR}_{\text {female vs male }}=1.55,95 \% \mathrm{CI} 1.10\right.$ to 

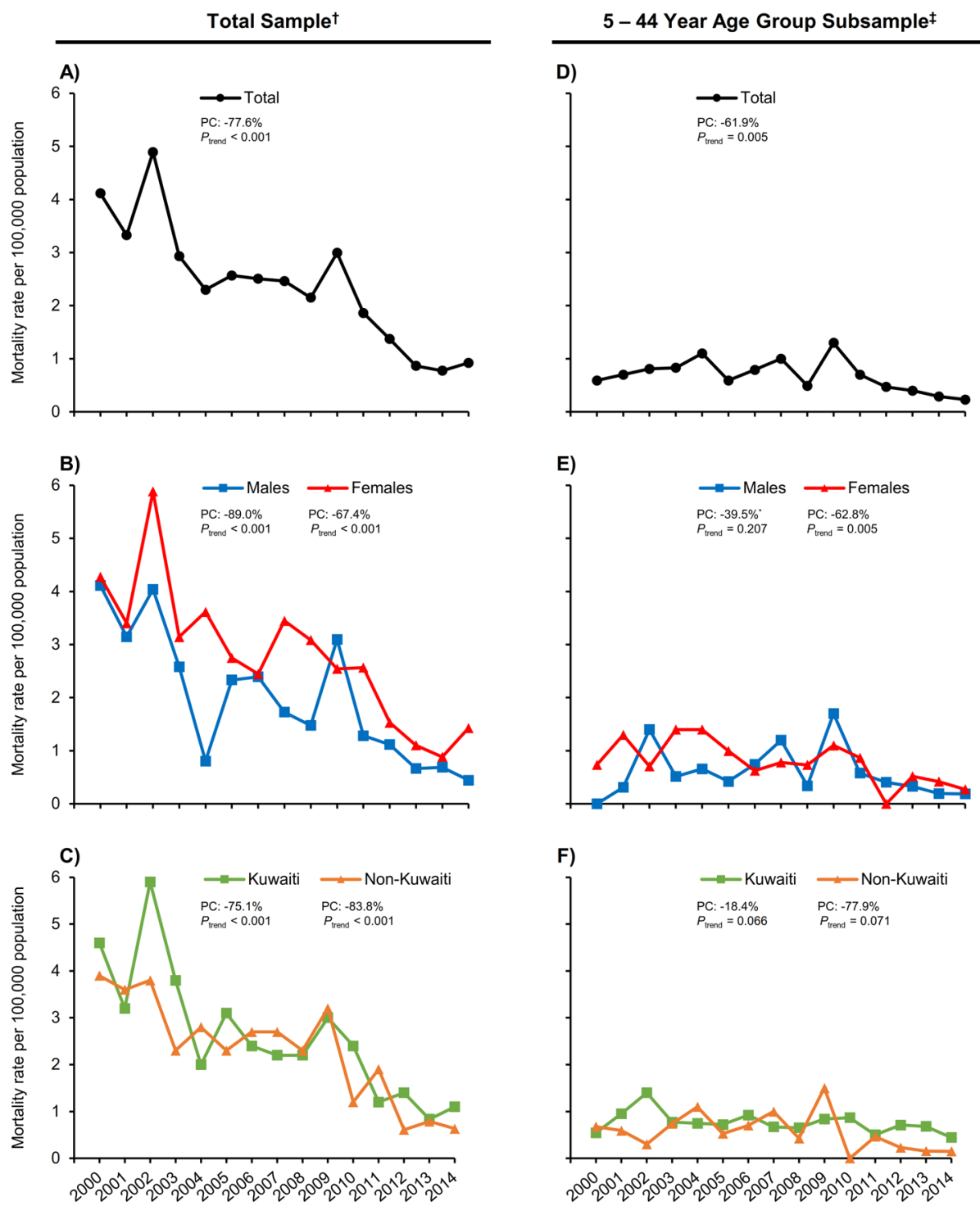

Figure 3 Trends in annual asthma mortality rates per 100000 population in Kuwait, 2000-2014. Asthma mortality rates in the ${ }^{\dagger}$ total study sample (A-C) and in a ${ }^{\ddagger}$ subsample restricted to those aged 5-44 years (D-F) are presented. (A) Trends in the total study sample. (B) Sex-stratified trends in the total study sample. (C) Nationality-stratified trends in the total study sample. (D) Trends in the total subsample. (E) Sex-stratified trends in the subsample. (F) Nationality-stratified trends in the subsample. Rates for the total population (A, D) are sex, age, and nationality model adjusted. The sex-stratified rates (B, E) are age and nationality model adjusted. Nationality-stratified rates (C, F) are age and sex model adjusted. Per cent change (PC) given as rate in 2014 versus rate in 2000. A negative PC value represents decrease between 2000 and 2014. $P$ values for linear trend were derived from Poisson regression analysis. "PC is given as rate in 2014 versus rate in 2001.

$2.40)$ and $\geq 65$ years $\left(\mathrm{aRR}_{\text {female vs male }}=1.50,95 \%\right.$ CI 1.06 to 2.12; see online supplementary table S2).

\section{DISCUSSION}

The purpose of this study was to examine national trends in hospitalisation and mortality due to asthma exacerbations in Kuwait using data from hospital discharge records and death certificates. This retrospective analysis of national data showed substantial reductions in asthma hospital admission and mortality rates in Kuwait between 2000 and 2014. Decreases in asthma hospital admissions and mortality rates over the 15-year study period were evident in both sexes, across different age groups and among Kuwaiti nationals and non-Kuwaiti subjects. On average, females compared with males and Kuwaitis compared with non-Kuwaitis had higher rates of asthma hospitalisation and mortality. Children aged $<5$ years and adults aged $\geq 65$ years had significantly higher hospitalisation rates compared with other age groups. Asthma mortality rate among subjects aged $\geq 65$ years was pronouncedly elevated compared with those aged $<65$ years. The observed decreasing trends in hospitalisation and mortality rates might be, in part, explained by improved management strategies and treatments and accessibility to high-quality healthcare services.

To our knowledge, there have been no recent investigations characterising trends in asthma hospital 


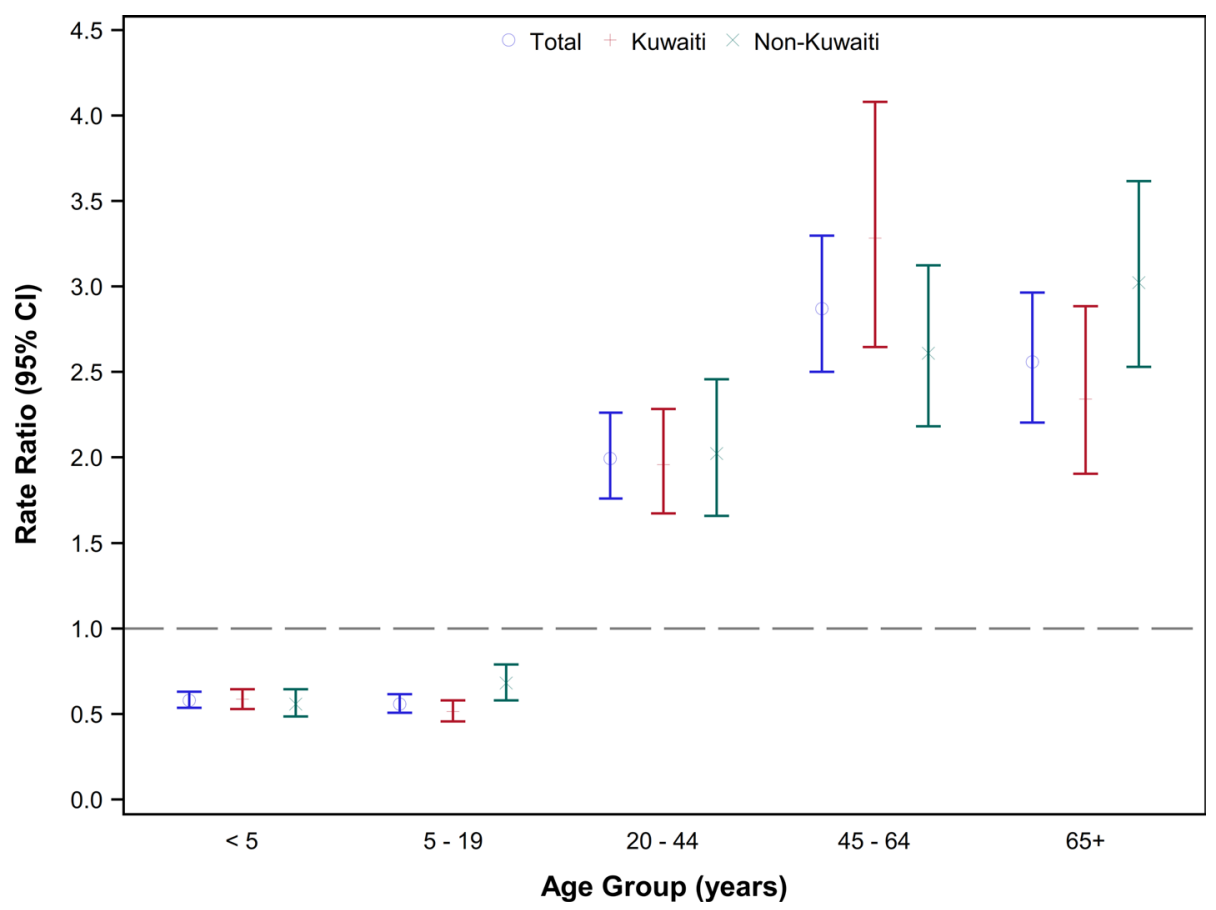

Figure 4 Rate ratios of hospital admission rates for asthma in females versus males by age group in Kuwait, 2000-2014. Rate ratios comparing females to males in the total population and by nationality are presented according to age groups. Rate ratios in the total population were adjusted for nationality.

admissions and mortality in Kuwait. A previous report estimated asthma hospitalisation and mortality rates in Kuwait during two 3-year periods: from 1987 to 1989 and 1992 to $1994 .^{12}$ In 1994 , asthma hospital admission and mortality rates were estimated to be 231.2 admissions and 1.36 deaths per 100000 population, respectively. ${ }^{12}$ In 2014, the latest year in the current analysis, there were 91.3 admissions and 0.9 deaths per 100000 population due to asthma exacerbations. Hence, this comparison clearly shows substantial reductions, specifically in asthma hospitalisation, between 1994 and 2014 in Kuwait.

A main finding in this report is that the estimated asthma hospital admission rate in the total population has reduced markedly from 180.8 admissions per 100000 population in 2000 to 91.3 admissions per 100000 population in 2014; translating to a $49.5 \%$ decrease. These declining trends were evident in both sexes, different age groups and Kuwaiti nationals and non-Kuwaiti subjects. Moreover, comparable declining trends were observed in the subsample restricted to those aged 5-44 years. Similar declining trends have been observed in different global regions. ${ }^{17}$ For instance, between 1997 and 2011 in Costa Rica, asthma hospital admission rate decreased by $53 \%$, with reductions observed among males and females as well as children and adults. ${ }^{18}$ Similar to our findings, reports from the USA, Spain Finland, and Norway have shown significant decreasing trends in asthma hospitalisation among the paediatric population. ${ }^{19-22} \mathrm{~A}$ report from the UK, looking at trends in asthma hospitalisation over a 50-year period from 1955 to 2004, indicated that asthma hospital admissions increased until the late 1980 s and have been declining thereafter. ${ }^{23}$ Similarly, a comprehensive report investigating trends in paediatric asthma hospital admissions in developed countries showed a peak in asthma hospitalisations around 19891990 and subsequently progressive declining trends. ${ }^{24}$

In regard to trends in asthma mortality, the current report showed that mortality related to asthma exacerbations has decreased by $77.6 \%$ between 2000 and 2014 in Kuwait in the total study sample and by $61.9 \%$ in the age group of 5-44years. In a global analysis of data from 188 countries, age-standardised asthma mortality rate decreased by $58.8 \%$ (95\% CI 39.0 to 69.0 ) between 1990 and $2015 .{ }^{1}$ Another study based on data from 46 countries, investigating trends in asthma mortality between 1993 and 2012, showed reductions in asthma deaths between 1993 and 2006, with no further changes from 2006 to $2012 .{ }^{15}$ These international data further support the observed decreases in asthma morality in Kuwait.

To this end, at a global level, the decreasing trends in asthma hospital admission and mortality rates over the past few decades can be explained, at least in part, by important changes in asthma medical care. These include developments in the pharmacological selectivity and delivery of adrenergic and corticosteroid drugs. ${ }^{23}$ Specifically, the wide availability and utilisation of longterm asthma control medications, such as inhaled corticosteroids. Moreover, the development of international, regional and local asthma management guidelines has also contributed to reducing asthma exacerbations and burden. The Global Initiative for Asthma, established in 1993, has continuously been developing evidence-based strategies for managing and preventing asthma that have been serving the international community at large. ${ }^{25}$ 
Collectively, improved therapeutics that are accessible and quality-assured, coupled with patient education and accessibility to quality healthcare services, have contributed to the declining trends in asthma hospitalisations and mortality.

Across the 15-year study period, sex-based, age-based and nationality-based disparities in asthma hospitalisations and mortality were observed. Overall, hospital admission rates were higher among females compared with males. However, these sex-based differences were found to vary across age groups. Among subjects aged $\leq 19$ years, males experienced more asthma hospitalisations compared with females, whereas among adults this observation is switched, where asthma hospitalisations become more frequent among females compared with males. Such observations have been reported in previous investigations. ${ }^{26}{ }^{27}$ Studies adjusting for the effect of potential confounders (eg, obesity, smoking, race) and comorbidities (eg, chronic obstructive pulmonary diseases) concluded that the age-stratified sex differences in asthma hospitalisations persisted even after adjustments. ${ }^{28-30}$ Hormonal factors have been speculated to differentially predispose males and females to disease development. ${ }^{31}$ For instance, oestrogen and progesterone were shown to alter pulmonary function and modify airway responsiveness. ${ }^{32}$ However, the exact mechanisms underlying the age-stratified sex disparity in hospitalisations due to asthma exacerbations are not fully elucidated.

Preschool children aged $<5$ years and adults aged $\geq 65$ years had, on average, higher asthma hospitalisation rates (426.5 and 405.1 admissions per 100000 population, respectively) over the study period than all other age groups; an observation that has been previously reported. ${ }^{33}$ However, careful interpretation of these age-specific rates should be exercised since diagnosis of asthma in early childhood is challenging ${ }^{25}$ and diagnostic overlap of asthma with acute bronchitis and bronchiolitis may occur, ${ }^{35}$ which could contribute to the high hospitalisation rates observed among preschool children. Among older adults, diagnostic substitution of chronic obstructive pulmonary disease for asthma may occur, leading to the observed elevated asthma hospital admission rates. Hence, as an attempt to lessen the effect of misclassification in the younger and older age groups, trends, in the current report, were additionally examined in a subsample restricted to individuals aged 5-44 years.

Geographical as well as racial/ethnic variations in asthma prevalence, hospital admissions and mortality have been reported. ${ }^{34}$ For instance, in the USA, African-Americans had higher asthma hospitalisation and mortality rates compared with white subjects. ${ }^{36}$ In the Scottish population, South Asians compared with Scottish white subjects had higher rates of asthma hospitalisation. ${ }^{37}$ The current analysis demonstrated differences in asthma hospitalisation rates based on nationality, with Kuwaiti nationals compared with non-Kuwaiti subjects having higher risk of asthma hospitalisation. In addition to the different racial/ethnic backgrounds of Kuwaiti and
non-Kuwaiti subjects, the different sex and age structure of the two populations (non-Kuwaitis mainly being of male gender and working age) could highly confound the observed nationality-based variation. However, both model-adjusted rates (see online supplementary table S1) and sex-standardised and age-standardised rates (see online supplementary table S3) showed that Kuwaiti nationals have higher risk of asthma hospitalisation compared with non-Kuwait subjects. Thus, the different sex and age structure of the two populations (Kuwaiti and non-Kuwait population) did not explain the observed nationality-based disparity. On the other hand, accessibility to healthcare, quality of care and treatment, patient education, and social, behavioural and environmental aspects could be some of the underlying factors for the observed nationality-based differences. ${ }^{38}$

This investigation provided, at a national level, a comprehensive understanding of trends and disparities in hospitalisations and mortality related to asthma exacerbations in Kuwait over a 15-year period. Nonetheless, we acknowledge some limitations, including misclassification of asthma-related hospitalisations or deaths, which is inevitable in epidemiological studies based on routinely collected data, such as data from hospital discharge records and death certificates. Such misclassification could either underestimate or overestimate the frequency of asthma hospitalisations and mortality. However, this is unlikely to fully account for the observed long-term declining trends and the sex-based, nationality-based and age-based differences. Moreover, throughout the study period, there were no changes in the ICD diseasecoding or coding rules; hence, avoiding the influence of diagnostic shift or procedural changes. Although governmental and private hospitals are required to report health and vital statistics to the NCHI, private hospitals tend not to fully comply with reporting requirements, which might lead to underestimating the burden of asthma hospitalisations and mortality. However, under-reporting, if any, by private hospitals does not directly impact the reported trends since the Ministry of Health has not relaxed the policies and requirements of reporting health and vital statistics. Moreover, to estimate the relative contributions of public and private hospitals to the data, we used the number of beds as a proxy measure due to the lack of information on the reporting hospitals in the analysed data. In 2014, there were $6962(86.8 \%)$ beds in public hospitals and $1058(13.2 \%)$ beds in private hospitals (Annual Health Report, NCHI, 2014); hence, we expect that the majority of the analysed data was reported by public hospitals and any under-reporting by private hospitals should not majorly impact results and conclusions of the current report. Another limitation is the inability of identifying multiple/repeated hospitalisations for each patient during the same year or over the study period due to the anonymous nature of the analysed data.

A further limitation is that the analysed data did not include information on race/ethnicity of patients, which has been shown to be an important factor in asthma 
hospitalisations and deaths. ${ }^{37}$ Rather, information on nationality (Kuwaiti vs non-Kuwaiti), a variable that could partially account for the race/ethnicity effect, was available and analysis comparing the two population groups showed that Kuwaiti nationals have higher hospitalisation and mortality rates compared with non-Kuwaiti subjects. On the other hand, a recent report has concluded that caution should be practised when interpreting declining trends in mortality rates in countries with high influx of migrant workforce, as the case in Kuwait, since such trends could be, in part, attributed to the healthy worker/ migrant effect. ${ }^{39}$ Although our findings are susceptible to such bias, results of stratified analysis showed that the declining trends in asthma hospital admission and mortality rates were similar in Kuwaiti and non-Kuwaiti subjects (see figures $1 \mathrm{C}$ and $3 \mathrm{C}$ ). Hence, the healthy worker/migrant effect does not explain the observed decreasing trends.

In conclusion, this study provided a national perspective on trends and burden of hospital admissions and mortality related to asthma exacerbations in Kuwait between 2000 and 2014. Trend analysis indicated that hospitalisation and mortality rates have significantly decreased over the 15 -year study period. The decreasing trends were evident in both sexes, all age groups and among Kuwaiti nationals and non-Kuwaiti subjects. Improvements in clinical care and development of targeted interventional strategies could further reduce rates of hospital admissions and mortality related to asthma exacerbations. Nevertheless, sex-based, age-based and nationality-based differences in asthma hospitalisation and mortality persisted across the study period. Therefore, future aetiological research is needed to address the factors underlying such disparities and gaps in knowledge.

Acknowledgements The authors thank staff at the National Center for Health Information, Ministry of Health, Kuwait, for providing the analyzed data in this manuscript. Specifically, they thank Dr Fahad Al-Khalifa, Dr Ali Sadek and Dr Gamal Makboul for their cooperation and support.

Contributors AHZ conceived and designed the epidemiological study, contributed to acquisition of data, analysed and interpreted the data, and drafted the manuscript. ATA conceived and designed the epidemiological study, interpreted the data and revised the manuscript. Both authors critically revised the manuscript for important intellectual content. The manuscript has been read and approved by both authors.

Funding The authors have not declared a specific grant for this research from any funding agency in the public, commercial or not-for-profit sectors.

Competing interests None declared.

Patient consent Not required.

Ethics approval The study was approved by the Standing Committee for Coordination of Health and Medical Research, Ministry of Health, Kuwait.

Provenance and peer review Not commissioned; externally peer reviewed.

Data sharing statement The data sets used and analysed in the current study are available from the corresponding author on reasonable request at: aziyab@hsc. edu.kw.

Open Access This is an Open Access article distributed in accordance with the Creative Commons Attribution Non Commercial (CC BY-NC 4.0) license, which permits others to distribute, remix, adapt, build upon this work non-commercially, and license their derivative works on different terms, provided the original work is properly cited and the use is non-commercial. See: http://creativecommons.org/ licenses/by-nc/4.0/ (c) Article author(s) (or their employer(s) unless otherwise stated in the text of the article) 2018. All rights reserved. No commercial use is permitted unless otherwise expressly granted.

\section{REFERENCES}

1. GBD 2015 Chronic Respiratory Disease Collaborators. Global, regional, and national deaths, prevalence, disability-adjusted life years, and years lived with disability for chronic obstructive pulmonary disease and asthma, 1990-2015: a systematic analysis for the Global Burden of Disease Study 2015. Lancet Respir Med 2017;5:691-706.

2. Asher MI, Montefort S, Björkstén B, et al. Worldwide time trends in the prevalence of symptoms of asthma, allergic rhinoconjunctivitis, and eczema in childhood: ISAAC Phases One and Three repeat multicountry cross-sectional surveys. Lancet 2006;368:733-43.

3. Lai CK, Beasley R, Crane J, et al. Global variation in the prevalence and severity of asthma symptoms: phase three of the International Study of Asthma and Allergies in Childhood (ISAAC). Thorax 2009;64:476-83.

4. Holgate ST, Wenzel S, Postma DS, et al. Asthma. Nat Rev Dis Primers 2015;1:15025.

5. Martinez FD, Vercelli D. Asthma. Lancet 2013;382:1360-72.

6. Fuhlbrigge A, Peden D, Apter AJ, et al. Asthma outcomes: exacerbations. J Allergy Clin Immunol 2012;129(3 Suppl):S34-48.

7. Sears MR. Epidemiology of asthma exacerbations. J Allergy Clin Immunol 2008;122:662-8. quiz 69-70.

8. Pawankar R, Canonica GW, Holgate ST, et al. Allergic diseases and asthma: a major global health concern. Curr Opin Allergy Clin Immunol 2012:12:39-41.

9. Owayed A, Behbehani N, Al-Momen J. Changing prevalence of asthma and allergic diseases among Kuwaiti children. An ISAAC Study (Phase III). Med Princ Pract 2008;17:284-9.

10. Ziyab AH. Prevalence and Risk Factors of Asthma, Rhinitis, and Eczema and Their Multimorbidity among Young Adults in Kuwait: A Cross-Sectional Study. Biomed Res Int 2017;2017:1-10.

11. Khadadah M. The cost of asthma in Kuwait. Med Princ Pract 2013;22:87-91.

12. Abul AT, Nair PC, Behbehanei NA, et al. Hospital admissions and death rates from asthma in Kuwait during pre- and post-Gulf War periods. Ann Allergy Asthma Immunol 2001;86:465-8.

13. Al-Awadhi JM, Alshuaibi AA. Dust fallout in Kuwait city: deposition and characterization. Sci Total Environ 2013:461-462:139-48.

14. De Bel-Air F. The demographic and economic framework of migration in Kuwait: Gulf Labour Market and Migration (GLMM) programme of the Migration Policy Center (MPC) and the Gulf Research Center (GRC), 2013.

15. Ebmeier S, Thayabaran D, Braithwaite I, et al. Trends in international asthma mortality: analysis of data from the WHO Mortality Database from 46 countries (1993-2012). Lancet 2017;390:935-45.

16. Ahmad OB, Boschi-Pinto C, Lopez AD, et al. Age standardization of rates: a new WHO standard - GPE Discussion Paper Series: 31 EIPI GPE/EBD. Geneva: World Health Organization, 2001.

17. Global Asthma Network. The Global Asthma Report 2014. Auckland, New Zealand: Global Asthma Network, 2014.

18. Soto-Martínez M, Avila L, Soto N, et al. Trends in hospitalizations and mortality from asthma in Costa Rica over a 12- to 15-year period. $J$ Allergy Clin Immunol Pract 2014;2:85-90.

19. Hasegawa K, Tsugawa Y, Brown DF, et al. Childhood asthma hospitalizations in the United States, 2000-2009. J Pediatr 2013;163:1127-33.

20. de Miguel-Díez J, Jiménez-García R, Hernández-Barrera V, et al. National trends in hospital admissions for asthma exacerbations among pediatric and young adult population in Spain (2002-2010). Respir Med 2014;108:983-91.

21. Säynäjäkangas $O$, Valmari $P$, Tuuponen $T$, et al. Trends in hospitalization for childhood asthma in Finland in 1996-2004. Acta Paediatr 2007;96:919-23.

22. Mikalsen IB, Skeiseid L, Tveit LM, et al. Decline in admissions for childhood asthma, a 26-year period population-based study. Pediatr Allergy Immunol 2015;26:750-5.

23. Anderson HR, Gupta R, Strachan DP, et al. 50 years of asthma: UK trends from 1955 to 2004. Thorax 2007;62:85-90.

24. Chawla J, Seear M, Zhang T, et al. Fifty years of pediatric asthma in developed countries: how reliable are the basic data sources? Pediatr Pulmonol 2012;47:211-9.

25. Bateman ED, Hurd SS, Barnes PJ, et al. Global strategy for asthma management and prevention: GINA executive summary. Eur Respir $J$ 2008;31:143-78. 
26. Chen $\mathrm{Y}$, Stewart $\mathrm{P}$, Johansen $\mathrm{H}$, et al. Sex difference in hospitalization due to asthma in relation to age. J Clin Epidemiol 2003;56:180-7.

27. Schatz M, Clark S, Camargo CA. Sex differences in the presentation and course of asthma hospitalizations. Chest 2006;129:50-5.

28. Lin RY, Ji R, Liao W. Age dependent sex disproportion in US asthma hospitalization rates, 2000-2010. Ann Allergy Asthma Immunol 2013;111:176-81.

29. Chasm RM, Pei YV, Pallin DJ, et al. Sex differences in risk of hospitalization among emergency department patients with acute asthma. Ann Allergy Asthma Immunol 2015;115:70-2.

30. Goto T, Tsugawa Y, Camargo CA, et al. Sex differences in the risk of hospitalization among patients presenting to US emergency departments with asthma exacerbation, 2010-2012. J Allergy Clin Immunol Pract 2016;4:149-51.

31. Klein SL. Immune cells have sex and so should journal articles. Endocrinology 2012;153:2544-50.

32. Haggerty CL, Ness RB, Kelsey S, et al. The impact of estrogen and progesterone on asthma. Ann Allergy Asthma Immunol 2003;90:284-91. quiz 91-3, 347.
33. Moorman JE, Akinbami LJ, Bailey CM. National surveillance of asthma: United States, 2001-2010. National Center for Health Statistics. Vital Health Stat 2012;3:1-67.

34. Mehal JM, Holman RC, Steiner CA, et al. Epidemiology of asthma hospitalizations among American Indian and Alaska Native people and the general United States population. Chest 2014;146:624-32.

35. Mansbach JM, Clark S, Teach SJ, et al. Children Hospitalized with Rhinovirus Bronchiolitis Have Asthma-Like Characteristics. J Pediatr 2016;172:202-4.

36. Gupta RS, Carrión-Carire V, Weiss KB. The widening black/white gap in asthma hospitalizations and mortality. J Allergy Clin Immunol 2006;117:351-8.

37. Sheikh A, Steiner MF, Cezard G, et al. Ethnic variations in asthma hospital admission, readmission and death: a retrospective, national cohort study of 4.62 million people in Scotland. BMC Med 2016;14:3.

38. Shah NM, Shah MA, Behbehani J. Ethnicity, nationality and health care accessibility in Kuwait: a study of hospital emergency room users. Health Policy Plan 1996;11:319-28.

39. Chaabna K, Cheema S, Mamtani R. Migrants, healthy worker effect, and mortality trends in the Gulf Cooperation Council countries. PLoS One 2017;12:e0179711. 